\title{
PENGEMBANGAN MODEL MANAJEMEN SEKOLAH BERBASIS MULTIKULTURAL PADA SEKOLAH MENENGAH ATAS (SMA) DI EKS KARESIDENAN PATI
}

\author{
Su'ad ${ }^{1}$
}

Prodi Magister Pendidikan Dasar, Fakultas Keguruan dan Ilmu Pendidikan Universitas Muria Kudus, Indonesia

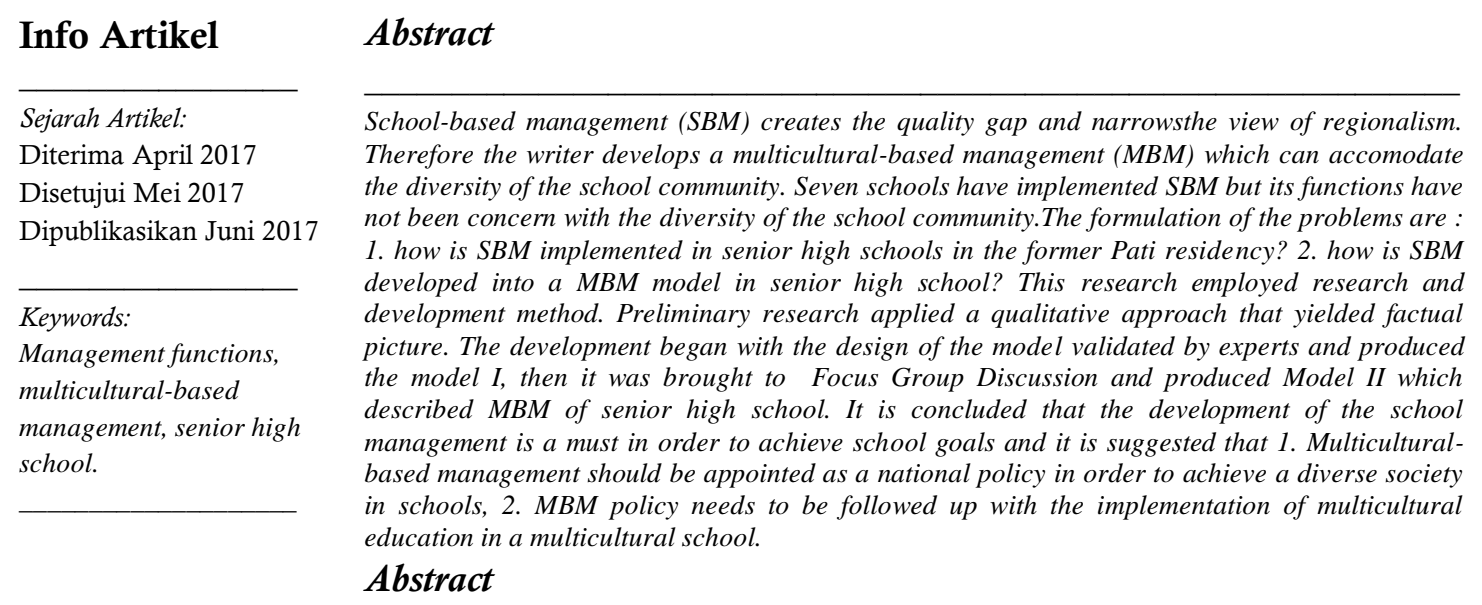

\begin{abstract}
Manajemen berbasis sekolah (SBM) menciptakan kesenjangan kualitas dan mempersempit pandangan regionalisme. Oleh karena itu penulis mengembangkan manajemen berbasis multikultural (MBM) yang dapat mengakomodasi keragaman komunitas sekolah. Tujuh sekolah telah menerapkan MBS namun fungsinya tidak memperhatikan keragaman masyarakat sekolah. Rumusan masalahnya adalah: 1. Bagaimana SBM diimplementasikan di sekolah menengah atas di bekas residensi Pati? 2. Bagaimana SBM berkembang menjadi model MBM di SMA? Penelitian ini menggunakan metode penelitian dan pengembangan. Penelitian pendahuluan menerapkan pendekatan kualitatif yang menghasilkan gambaran faktual. Perkembangan dimulai dengan disain model yang divalidasi oleh para ahli dan menghasilkan model I, kemudian dibawa ke Focus Group Discussion dan diproduksi Model II yang menggambarkan MBM SMA. Disimpulkan bahwa pengembangan manajemen sekolah adalah suatu keharusan untuk mencapai tujuan sekolah dan disarankan agar 1. Manajemen berbasis budaya harus ditunjuk sebagai kebijakan nasional untuk mencapai masyarakat yang beragam di sekolah, 2. Kebijakan MBM perlu ditindaklanjuti dengan penerapan pendidikan multikultural di sekolah multikultural.
\end{abstract}

(C) 2017 Universitas Muria Kudus

\footnotetext{
Alamat korespondensi:

Program Studi Pendidikan Guru Sekolah Dasar

Fakultas Keguruan dan Ilmu Pendidikan Universitas Muria Kudus

Kampus UMK Gondangmanis, Bae Kudus Gd. L. 1t I PO. BOX 53

Kudus

Tlp (0291) 438229 ex.147 Fax. (0291) 437198

E-mail: $\underline{\text { suad@umk.ac.id }}$
}

p-ISSN 2087-9385 e-ISSN 2528-696X 


\section{PENDAHULUAN}

Manajemen berbasis sekolah (MBS) di era otonomi daerah mengalami banyak kendala akibat dari kebijakan pemerintah daerah dalam bidang pendidikan yang merugikan. Permasalahan yang muncul dari kebijakan tersebut misalnya pembatasan siswa luar daerah dalam memasuki sekolah melalui penerimaan peserta didik baru (PPDB) sebanyak 5\% dari kuota, mutasi antar daerah bagi guru yang sangat sulit, dan semakin menguatnya semangat kedaerahan dan etnisitas sehingga mempersempit pandangan warga sekolah terhadap lingkungannya. Semangat kedaerahan dan kesukuan (etnisitas) menyebabkan meningkatnya semangat primordialisme. Sementara tantangan global menuntut lulusan sekolah menengah atas (SMA) harus dapat bersaing, bergaul di lingkungan internasional yang luas dari berbagai keberagaman baik agama, gender, etnis, sosial ekonomi, sosial budaya dan sebagainya.

Konflik sosial di berbagai daerah juga sering terjadi disebabkan oleh permasalahan agama, ras, etnis, bahasa, sosial ekonomi, gender, sosial budaya dan sebagainya (Wasino, 2009). Sekolah menengah atas (SMA) sebagai bagian dari masyarakat yang beragam juga sering terjadi permasalahan yang diakibatkan oleh perbedaan tersebut, karena warga sekolah mencerminkan kondisi masyarakatnya. Berdasarkan observasi pelaksanaan manajemen sekolah menengah atas (SMA) di eks karesidenan pati masih terdapat beberapa permasalahan yang menyangkut perlakuan yang diskriminatif, baik dalam aspek agama, ras, sosial ekonomi, sosial budaya, bahasa dan sebagainya. Oleh karena itu sekolah perlu memiliki pengaturan pengelolaan sekolah yang dapat menghindarkan adanya konflik sosial dan mewujudkan sekolah yang saling menghargai dan menghormati antar warga sekolah baik guru, siswa, kepala sekolah, komite sekolah dan sebagainya dengan peran dan mekanisme yang jelas. Hal tersebut hendaknya mendapatkan perhatian melalui pengembangan manajemen sekolah berbasis multikultural agar tujuan sekolah dapat tercapai.

Pelaksanaan manajemen sekolah berbasis multikultural hendaknya mempehatikan fungsi-fungsi manajemennya. Hal ini sejalan dengan pendapat Terry (2012:15-16) perlu mempertimbangkan input sekolah antara lain : (1) keberagaman warga sekolah baik guru, karyawan, siswa, komite sekolah, (2) penjaminan mutu sebagai sekolah multikultural dan (3) kebutuhan layanan pendidikan yang beragam. Dengan demikian akan selaras dengan amanah UndangUndang tentang Sistem Pendidikan Nasional nomor 20 Tahun 2003 pasal 4 bahwa pendidikan nasional diselenggarakan secara demokratis, berkeadilan serta tidak diskriminatif dengan menjunjung tinggi hak asasi manusia, nilai-nilai keagamaann, nilai-nilai kultur, dan kemajemukan bangsa (UU Nomor 20 Tahun 2003).

Bertolak dari hal tersebut, menarik untuk melakukan penelitian tentang manajemen berbasis sekolah (MBS) dengan dikembangkan menjadi manajemen sekolah berbasis multikultural pada sekolah menengah atas (SMA).

\section{METODE PENELITIAN}

Pengembangan model manajemen sekolah berbasis multikultural ini dilakukan melalui pendekatan Penelitian dan Pengembangan (Research and Development / $R \& D$ ) yang dimodifikasi. Mengingat dalam model manajemen sekolah berbasis multkultural pada sekolah menengah atas (SMA) di eks karesidenan Pati tidak mungkin dilakukan uji coba lapangan, maka dalam penelitian ini hanya dilakukan validasi pakar / ahli baik pakar manajemen pendidikan dan pakar pendidikan multikultural serta dilanjutkan dengan focus group discussion (FGD) yang dihadiri para kepala sekolah menengah atas di korwil Pati plus. Prosedur pengembangan mengacu kepada pendapat Borg \& Gall (2007: 774-787) dengan urutan sebagai berikut : (1) menentukan produk; (2) kajian teoritis; (3) perencanaan pengembangan; (4) pengembangan model awal; (5) validasi model; (6) penemuan produk akhir.

\section{HASIL DAN PEMBAHASAN}

Model manajemen sekolah berbasis multikultural pada sekolah menengah atas (SMA) di eks karesidenan Pati dikembangkan dari model faktual yang merupakan hasil penelitian awal. Model faktual tersebut adalah model manajemen sekolah yang saat ini dijalankan di sekolah Menengah atas (SMA) di eks karesidenan Pati, yaitu manajemen sekolah yang dijalankan berdasarkan manajemen berbasis sekolah dan diperkuat dengan peraturan menteri pendidikan nasional (permendiknas nomor 19 tahun 2007). Adapun gambar model faktual tersebut digambarkan sebagaimana berikut: 


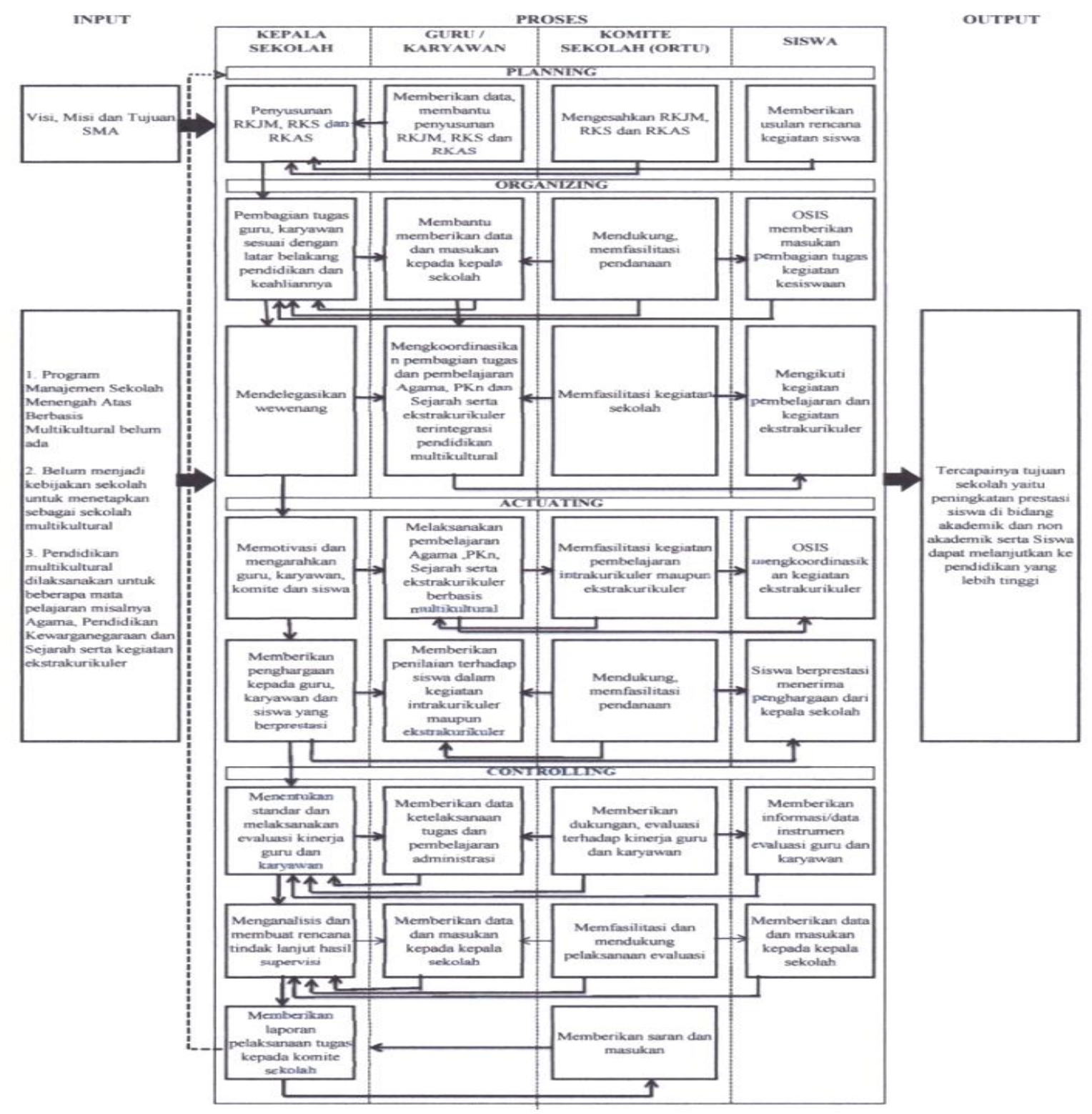

Gambar 1: Model Manajemen Sekolah Menengah Atas (SMA) Faktual

Dari gambar model manajemen sekolah faktual dapat dimengerti bahwa tahapan fungsi manajemen sekolah telah dijalankan dengan baik, namun belum memasukkan aspek keberagaman warga sekolah baik unsur guru, karyawan, peserta didik, komite sekolah dan sebagainya sebagai faktor penting yang harus dipertimbangkan. Mengacu kepada pendapat Sugiyono (2009:412) dalam bidang pendidikan, bahwa produk-produk yang dihasilkan melalui penelitian dan pengembangan (R\&D) antaralain dapat berupa metode mengajar, media pendidikan, sistem pembinaan pegawai, sistem penggajian, model manajemen dan sebagainya, maka model yang dikembangkan dalam penelitian ini adalah model manajemen yaitu model manajemen sekolah berbasis multikultural pada sekolah menengah atas (SMA).

Model faktual selanjutnya dikembangkan dengan diinterpretasikan, dianalisis, dan diprediksikan berdasarkan kajian teori-teori yang relevan menjadi sebuah desain model dengan memasukkan faktor keberagaman sebagai faktor penting penentu keberhasilan manajemen sekolah. Adapun desain model penulis rancang sebagaimana gambar tersebut di bawah ini: 


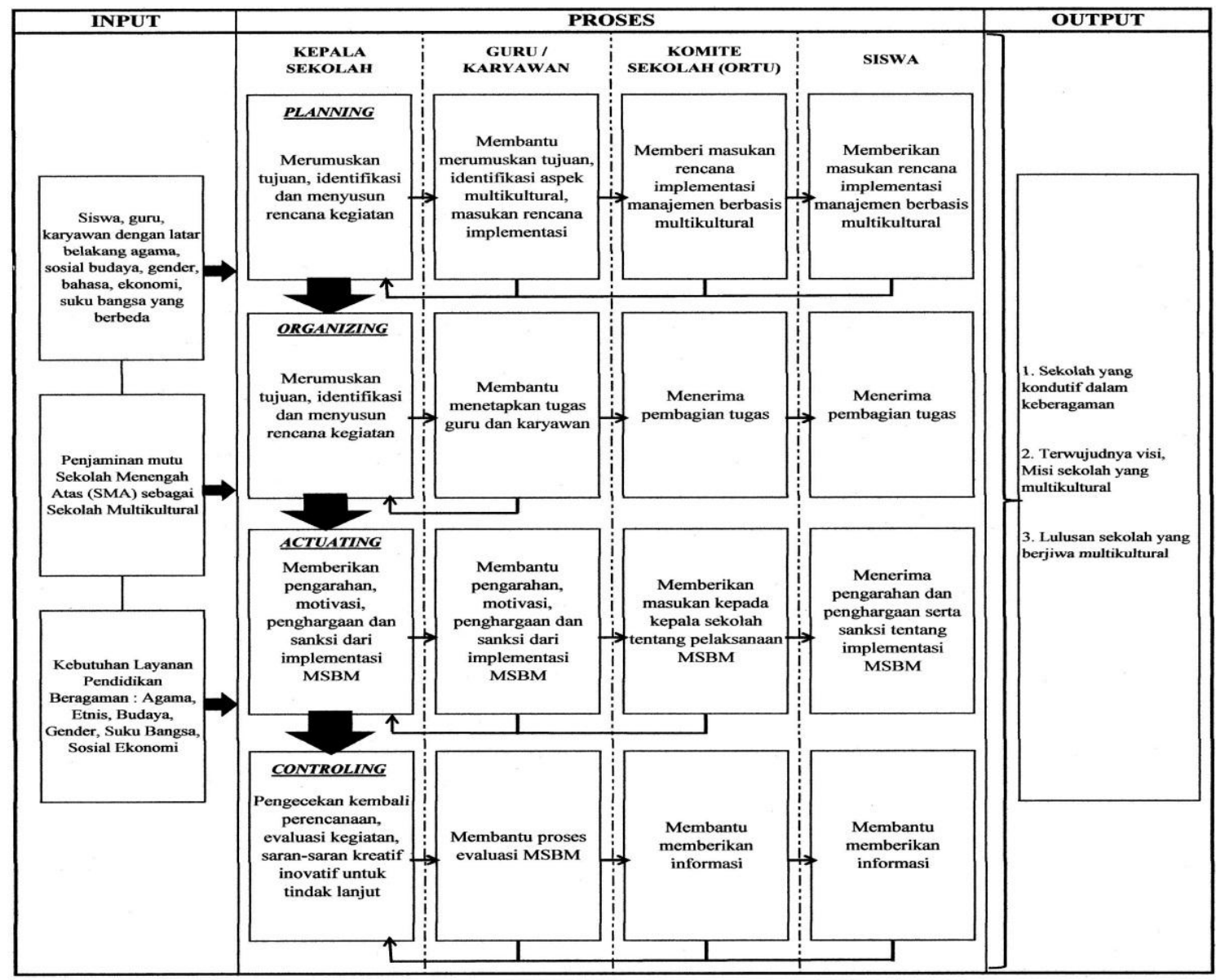

Gambar 2: Desain Model Manajemen Sekolah Berbasis Multikultural Pada Sekolah Menengah Atas (SMA)

Selanjutnya desain model setelah divalidasi pakar manajemen pendidikan dan pakar pendidikan multikultural diperoleh model manajemen sekolah berbasis multikultural I hasil validasi pakar / ahli.

Validasi desain merupakan proses kegiatan untuk menilai apakah rancangan produk secara rasional akan lebih efektif dari yang lama atau tidak (Sugiyono, 2009: 414). Validasi produk dalam manajemen sekolah berbasis multikultural ini dilakukan dengan meminta masukan / saran kepada beberapa pakar atau tenaga ahli yang sudah berpengalaman untuk menilai produk baru yang penulis rancang tersebut. Kegiatan ini penulis laksanakan dengan meminta masukan / saran kepada beberapa pakar manajemen pendidikan dan pakar pendidikan multikultural. Adapun gambar manajemen sekolah berbasis multikultural sebagai hasil validasi pakar / ahli adalah sebagai berikut: 


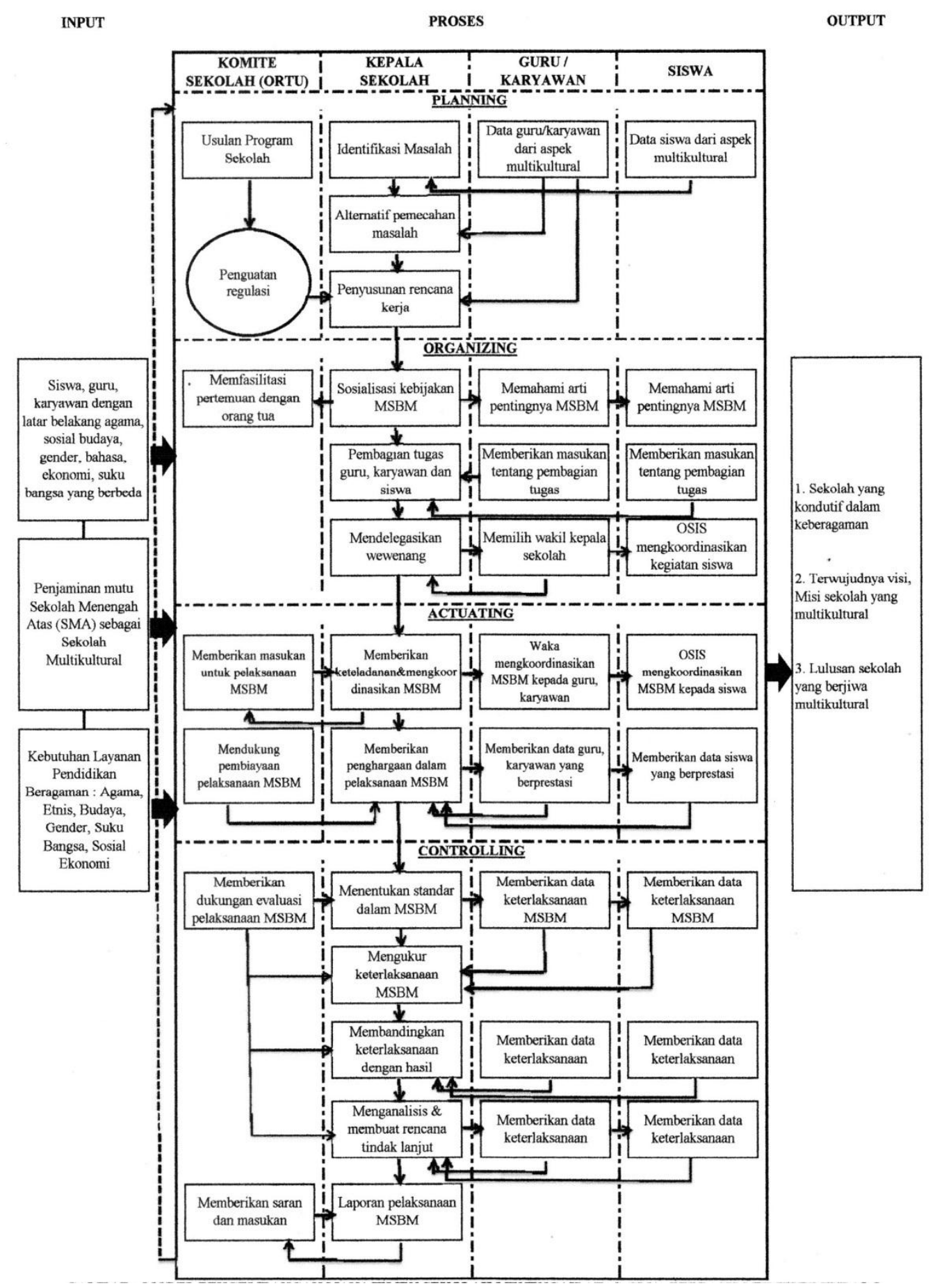

Gambar 3: Model Manajemen Sekolah Berbasis Multikultural I (Validasi Pakar)

Model manajemen sekolah berbasis multikultural pada sekolah menengah atas (SMA) hasil validasi pakar tersebut selanjutnya dibawa kepada diskusi terbatas focus group discussion (FGD) yang terdiri para kepala sekolah menengah atas (SMA) korwil Pati plus yang jumlahnya sembilan orang. Hasilnya adalah model manajemen sekolah berbasis multikultural pada sekolah menengah atas Final sebagaimana tersebut di bawah ini: 
INPUT

PROSES

OUTPUT

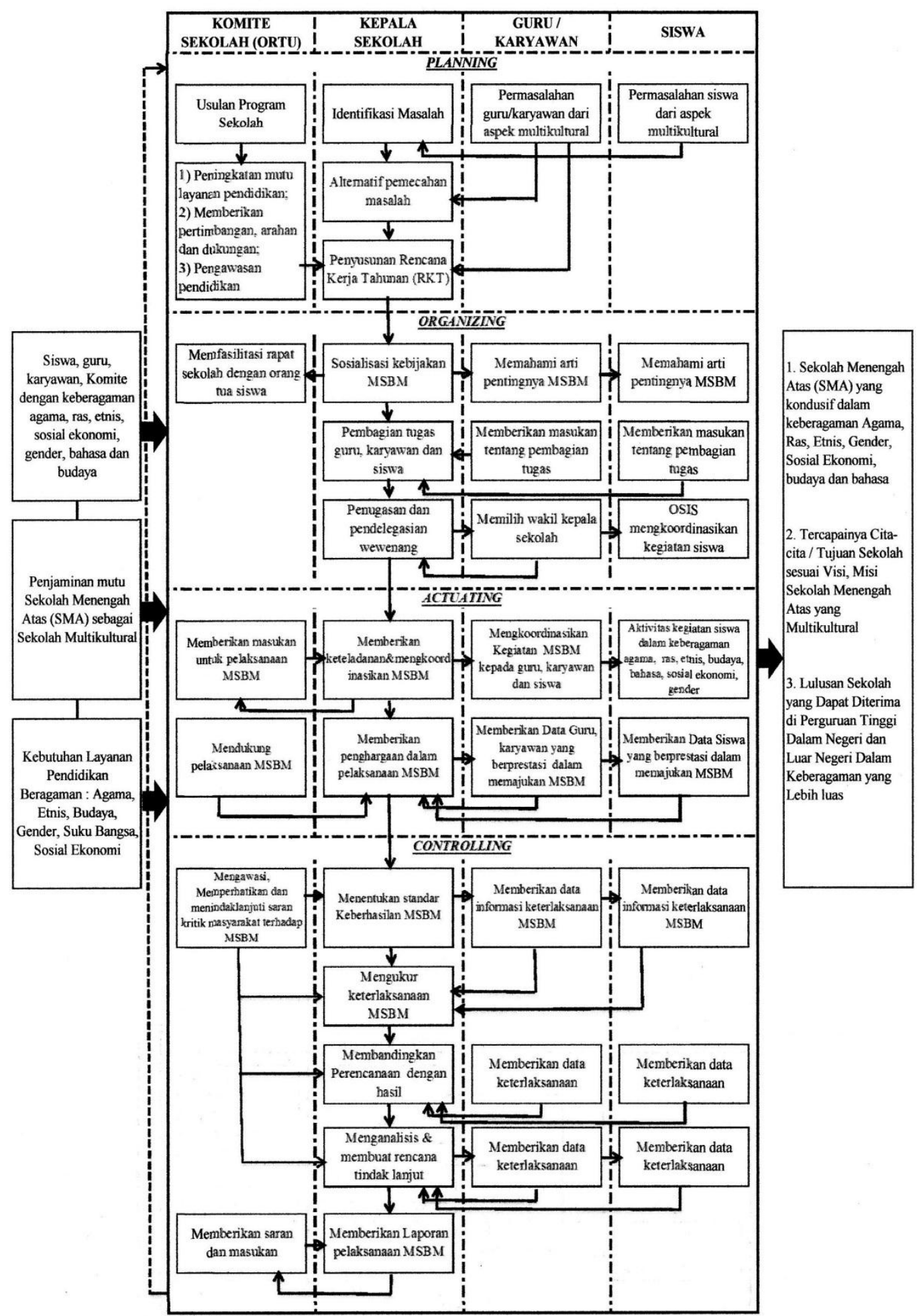

Gambar 4: Model Manajemen Sekolah Berbasis Multikultural II (FGD / Final) 


\section{SIMPULAN}

Manajemen berbasis sekolah yang diimplementasikan pada era otonomi daerah perlu dikembangkan menjadi Manajemen sekolah berbasis multikultural, karena dengan model manajemen sekolah berbasis multikultural, keberagaman warga sekolah dapat diakomodir kepentingannya tanpa kebijakan yang diskriminatif dan akan tercipta sekolah yang kondusif serta dapat mencapai cita-cita sekolah (visi dan misi sekolah).

Berdasarkan simpulan tersebut disarankan: Pertama manajemen sekolah berbasis multikultural perlu dijadikan pertimbangan untuk dilaksanakan di berbagai sekolah menengah atas, mengingat menajemen berbasis sekolah di era otonomi daerah menemui banyak kendala, sehingga berbagai kendala tersebut dapat diatasi.

Kedua,perlu kerjasama berbagai pihak di dalam sekolah untuk mewujudkan sekolah yang kondusif dengan tahapan fungsi manajemen sekolah yang telah disiapkan mekanisme kerja organisasinya dan dapat dipedomani dengan mudah melalui manajemen sekolah berbasis multikultural.

\section{DAFTAR PUSTAKA}

Borg, R.W. Gall, M.D. 2007. Educational Research; An Introduction, New YorkLondon: Longman Inc.

Pedoman Penjaminan Mutu Sekolah/Madrasah Bertaraf Internasional Pada Jenjang Pendidikan Dasar dan Menengah.2009. Depdiknas.

Peraturan Menteri Pendidikan Nasional nomor 19 Tahun 2007 tentang Standar Pengelolaan.

Sugiyono. 2009. Metode Penelitian Pendidikan, Pendekatan Kuantitatif, Kualitatif, dan $R \& D$. Bandung : Alfabeta.

Terry, G. R. 2012. Prinsip-Prinsip Manajemen. Jakarta: PT Bumi Aksara.

Wasino, at al. 2009. Integrasi Sosial Dalam Negara Bermasyarakat Majemuk Pada Era Global. Proceeding Seminar Internasional. Semarang: Fakultas Ilmu Sosial Universitas Negeri Semarang.

Undang-undang Sistem Pendidikan Nasional nomor 20 Tahun 2003. 